Volume. 4 Nomor. 1

Periode: Januari - Juni 2020; hal. 34-40

p-ISSN : 2580-1112; e-ISSN : 2655-6669

Copyrighr @2020

Penulis memiliki hak cipta atas artikel ini

journal homepage: https://ejournal.akperfatmawati.ac.id

DOI:10.46749/jiko.v3i2.38
Jurnal Ilmiah Keperawatan Orthopedi

(JIKO)

Article history:

Received: Desember 12, 19

Revised: September 07, 20

Accepted: September 09, 20

\title{
Ketepatan Pemberian Obat Oleh Perawat Dipengaruhi Lingkungan Kerja Di Ruang Rawat Inap Rsud Kanujoso Balikpapan
}

Kata kunci: Gaya kepemimpinan, Lingkungan kerja, Ketepatan Pemberian Obat

\begin{abstract}
Work environment consists of leadership style and organizational culture. Leadership style is a way for leaders to influence others. While organizational culture is also believed to be a determining factor for the success of performance that has an association with service quality. The quality of hospital services can be seen from the speed of service, friendliness, effectiveness of actions, and conditions that can create comfort for patients and visitors. One form of this quality is measured by the accuracy in drug administration. Six rights in giving medicines include the right client, medicine, dosage, time, method / route and added with proper documentation so that medication error does not occur. Chi-Square test results of leadership style and organizational culture b obtained $p$ value (0.003; 0.001). it means that there is an influence of leadership style and organizational culture with the accuracy of drug delivery.
\end{abstract}

Keywords: Work Environment, work environment, Accuracy Dispensing

${ }^{1}$ e-mail: Pf561@umkt.ac.id 


\section{Pendahuluan}

Kualitas pelayanan suatu rumah sakit dapat diidentifikasi dari kinerja para perawat sebagai salah satu tenaga kesehatan. Porsi perawat di rumah sakit adalah yang terbanyak sehingga perawat berperan penting dalam mendukung terciptanya kualitas pelayanan.

Hal ini terkait dengan keberadaan perawat yang bertugas selama 24 jam melayani pasien dan jumlah perawat yang mendominasi tenaga kesehatan di rumah sakit, yaitu sekitar 40-60\% (Swansburg, 2010).

Salah satu tugas perawat adalah melakukan pemberian obat kepada pasien sebagai bentuk pertanggungjawaban secara legal atas tindakan yang telah dilakukan. Penerapan prinsip enam tepat (six rights) oleh perawat akan mempengaruhi keberhasilan pengobatan.

Hal ini terutama akan tampak pada pasien yang dirawat di ruang rawat inap. Seorang perawat harus memberikan berbagai macam obat kepada beberapa pasien rawat inap yang berbeda, yang menjadi tanggung jawabnya.perawat harus menerapkan prinsip "enam tepat" tersebut untuk menghindari kesalahan pemberian obat (Hidayat dan Uliyah, 2014).

Permasalahan muncul ketika berdasarkan hasil pengamatan peneliti selama residensi dan data dari safety centre di RSUD Kanujoso Djatiwibowo Balikpapan terdapat kenaikan jumlah ketidaktepatan pemberian obat baik dalam segi waktu, orang, dosis, dan lokasi dari tahun ke tahun dengan data sebagai berikut.

Kecilnya data tingkat kejadian medication error salah satunya bisa disebabkan oleh budaya keselamatan pasien di RSUD Dr. Kanujoso Djatiwibowo Balikpapan yang belum optimal, hal ini dapat dilihat dari hasil kuesioner dengan sampel 19 orang perawat bahwa terdapat $57.1 \%$ responden tidak pernah melaporkan adanya kesalahan yang terjadi dan Responden yang takut disalahkan kalau melapor sebanyak $38.1 \%$. Responden mendukung keselamatan pasien dan harapan adanya monitoring serta evaluasi, ini didukung oleh $47.6 \%$ responden.

Ketepatan pemberian obat merupakan salah satu bentuk kinerja perawat. Walaupun dalam hal ini merupakan suatu bentuk tugas limpahan dari apoteker atau farmasi, namun kegiatan ini lebih sering dilakukan oleh perawat dan bahkan seolah-olah merupakan tugas wajib perawat dibandingkan dengan peran dan fungsi perawat yang lain, dalam hal ini juga peran perawat dalam pemberian obat merupakan peran yang vital didalam pencapaian derajat kesembuhan dan kesehatan bagi pasien dilihat dari latar belakang kejadian yang dapat ditimbulkan apabila hal ini tidak dilakukan sesuai SOP (Robbins , 2013).

\section{Metode Penelitian}

Penelitian ini bertujuan untuk menganalisis hubungan lingkungan kerja dan role stress dengan ketepatan pemberian obat oleh perawat di ruang rawat inap RSUD Kanudjoso Djatiwibowo Balikpapan. Penelitian ini menggunakan jenis penelitian kuantitatif dengan metode cross sectional.

Populasinya adalah perawat yang bekerja di ruang rawat inap RSUD Dr Kanujoso Djatiwibowo Balikpapandan merupakan pegawai tetap rumah sakit, atau tenaga honorer yang telah bekerja lebih dari 1 tahun, dan perawat yang sudah pernah mengikuti uji kompetensi dasar keperawatan, yang memenuhi kriteria tersebut ada sebanyak 258 perawat.

Sampel adalah perawat yang diambil menjadi sampel yang memenuhi kriteria inklusi: perawat Pelaksana yang bertugas di ruang rawat inap, masa kerja di pelayanan rawat inap minimal 1 tahun dan perawat pelaksana yang sudah 
pernah mengikuti ujian kompetensi perawat dasar..

Metode pengambilan sampel berbasis pada probabilitas dengan metode random sederhana. Pengambilan jumlah sampel dilakukan dengan menggunakan rumus Lemeshow diperoleh sampel sebanyak 116 perawat. Ruangan-ruangan yang dipakai oleh peneliti untuk diambil datanya antara lain

\section{Hasil Penelitian}

Distribusi Frequensi Karakteristik Perawat RSUD Kanujoso Djatiwibowo Balikpapan Tahun 2018

\begin{tabular}{|c|c|c|c|}
\hline $\begin{array}{l}\mathbf{N} \\
\mathbf{0}\end{array}$ & Karakteristik & $\begin{array}{c}\text { Frek } \\
\text { uens } \\
\text { i }\end{array}$ & $\begin{array}{l}\text { Persent } \\
\text { ase }(\%)\end{array}$ \\
\hline \multirow[t]{3}{*}{1} & Jenis kelamin & & \\
\hline & - Laki-laki & 18 & 13,3 \\
\hline & - Perempuan & 117 & 86,7 \\
\hline \multirow[t]{6}{*}{2} & Umur & & \\
\hline & - Termuda $=21$ tahun & & \\
\hline & - Tertua $=46$ tahun & & \\
\hline & $\begin{array}{l}\text { - Rata-rata }=26,72 \\
\text { tahun }\end{array}$ & & \\
\hline & Kelompok umur & 84 & 62,2 \\
\hline & $\begin{array}{l}-\leq 27 \text { tahun } \\
->27 \text { tahun }\end{array}$ & 51 & 37,8 \\
\hline \multirow[t]{3}{*}{3} & Pendidikan & & \\
\hline & - D3 keperawatan & 118 & 87,4 \\
\hline & - S1 keperawatan & 17 & 12,6 \\
\hline \multirow[t]{8}{*}{4} & Lama kerja & & \\
\hline & - Terendah $=1$ tahun & & \\
\hline & - Tertinggi $=18$ tahun & & \\
\hline & - Rata-rata $=8$ tahun & & \\
\hline & Kelompok lama kerja & & \\
\hline & $-\leq 8$ tahun & 81 & 60,0 \\
\hline & $->8$ tahun & 54 & 40,0 \\
\hline & Total & 135 & 100 \\
\hline
\end{tabular}

adalah ruang Flamboyan A, B, C, D, E, Soka, Kemuning, Karamunting, Mawar Melati, dan juga anggrek hitam lantai 4. Hasil uji reliabilitas dari masing-masing variabel dalam penelitian ini ditunjukkan kuesiner gaya kepeminpinan tranformasional, gaya kepemimpinan transasional, budaya organisasi $(0,969$; 0,927 dan 0,816).

Tabel menunjukkan bahwa mayoritas responden berjenis kelamin perempuan $(86,7 \%)$, umur responden termuda adalah 21 tahun dan tertua 46 tahun dengan rata-rata 26,72 tahun, ketika umur responden ini dikelompokkan berdasarkan rata-rata umur responden, umur responden lebih banyak yang berada di bawah rata-rata yaitu sebanyak $84(62,2 \%)$ responden memiliki umur $\leq 27$ tahun, dan sisanya $51(37,8 \%)$ responden memiliki umur di atas 27.

Berdasarkan tingkat pendidikan mayoritas responden berpendidikan D3 keperawatan $(87,4 \%)$, dan mayoritas telah berprofesi sebagai perawat di RSUD Kanujoso Djatiwibowo Balikpapan selama $\$ 8$ Tahun $(60,0 \%)$.

Rincian Temuan Kesalahan Pemberian Obat oleh Perawat di RSUD Kanujoso Djatiwibowo Balikpapan Tahun 2018

\begin{tabular}{|l|l|l|l|}
\hline No & $\begin{array}{c}\text { Ketepatan } \\
\text { Pemberian } \\
\text { Obat }\end{array}$ & \multicolumn{1}{|c|}{ Implementasi } & \multicolumn{1}{|c|}{ Hasil penelitian } \\
\hline 1. & Benar pasien & $\begin{array}{l}\text { Perawat mencocokan nama } \\
\text { yang tertera di obat dengan } \\
\text { identitas di gelang pasien }\end{array}$ & $\begin{array}{l}\text { Sekitar 43,0\% perawat tidak melakukan } \\
\text { pengecekan gelang identitas pasien yang } \\
\text { disesuaikan ndengan buku RPO dan } \\
\text { tanggal lahir pasien, sehingga sangat rawan } \\
\text { untuk terjadi salah pemberian obat ke } \\
\text { pasien lain atau pasien yang namanya } \\
\text { mirip. }\end{array}$ \\
\hline 2. & Benar obat & $\begin{array}{l}\text { Perawat mencocokkan } \\
\text { jenis/nama obat yang ada di }\end{array}$ & $\begin{array}{l}15,6 \% \text { perawat tidak mencocokkan nama } \\
\text { di status dengan obat yang diberikan, untuk }\end{array}$ \\
\hline
\end{tabular}




\begin{tabular}{|c|c|c|c|}
\hline & & $\begin{array}{l}\text { status pasien dengan obat } \\
\text { yang akan diberikan untuk } \\
\text { pasien }\end{array}$ & $\begin{array}{l}\text { perawat yang tugas sore dan malam } \\
\text { harusnya mengecek ulang terapi obat-obat } \\
\text { yang diteruskan ataupun dihentikan setelah } \\
\text { dokter melakukan visite. }\end{array}$ \\
\hline 3. & Benar dosis & $\begin{array}{llr}\text { Perawat } & \text { mencocokkan/ } \\
\text { menghitung } & \text { ulang jumlah } \\
\text { dosis yang ada di } & \text { status } \\
\text { pasien dengan obat yang } \\
\text { akan diberikan untuk pasien }\end{array}$ & $\begin{array}{l}13,3 \% \text { perawat tidak mencocokkan/ } \\
\text { menghitung ulang dosis yang di status } \\
\text { dengan obat yang diberikan, untuk perawat } \\
\text { yang tugas sore dan malam harusnya } \\
\text { mengecek ulang terapi obat-obat yang } \\
\text { diteruskan ataupun dihentikan setelah } \\
\text { dokter melakukan visite. }\end{array}$ \\
\hline 4. & $\begin{array}{l}\text { Benar } \\
\text { cara/rute }\end{array}$ & $\begin{array}{l}\text { Perawat melihat kembali } \\
\text { cara pemberian obat yang } \\
\text { ada di status pasien dengan } \\
\text { alat yang akan disiapkan } \\
\text { untuk pemberian obat untuk } \\
\text { pasien }\end{array}$ & $\begin{array}{l}\text { Pemberian obat melalui parenteral atau } \\
\text { selang infuse pasien hendaknya dilakukan } \\
\text { di tempat penyuntikan yang benar dan } \\
\text { menggunakan selang infuse yang benar. } \\
\text { Akibat pemberian obat di lokasi yang } \\
\text { kurang tepat akan mengakibatkan resiko } \\
\text { terjadinya phlebitis yang cukup besar dan } \\
\text { juga mengakibatkan pasien lebih cenderung } \\
\text { merasa nyeri pada saat dilakukan injeksi. } \\
\text { (Wayunah, 2011) } \\
\text { Ada sekitar 19,3\% perawat yang tidak } \\
\text { benar cara/rute diantaranya tidak } \\
\text { menggunakan alcohol swab, sarung tangan, } \\
\text { dan melakukan cuci tangan sebelum dan } \\
\text { sesudah tindakan yang dilakukan kepada } \\
\text { pasien }\end{array}$ \\
\hline 5. & Benar waktu & $\begin{array}{l}\text { Perawat mengecek waktu } \\
\text { pemberian obat terakhir } \\
\text { pasien yang dicocokkan } \\
\text { dengan status pasien }\end{array}$ & $\begin{array}{l}\text { Pemberian obat yang harus mundur } \\
\text { beberapa jam akibat : stok di depo kosong, } \\
\text { keterlambatan pengiriman dari depo, obat } \\
\text { yang sebelumnya belum habis padahal } \\
\text { harusnya dijadwal sudah harus habis (obat- } \\
\text { obat yang pemberiannya menggunakan } \\
\text { infuse), jalur infuse yang bermasalah } \\
\text { (adanya phlebitis) sehingga perlu diganti, } \\
\text { dan penggantian ini biasanya menunggu } \\
\text { pemberian obat seluruh pasien selesai } \\
\text { terlebih dahulu baru dipasang infuse baru. } \\
\text { Pemberian obat oral yang kurang } \\
\text { pengawasan (dibagikan } 2 \text { jam sebelum } \\
\text { waktu minum dan } 17,8 \% \text { tidak dicek lagi } \\
\text { apakah pasien meminumnya atau tidak) } \\
\text { sehingga ada dijumpai oleh peneliti bahwa } \\
\text { pasien memiliki stok obat yang berlebihan } \\
\text { di tempat tidurnya karena pasien tidak } \\
\text { pernah mau meminum obat yang diberikan } \\
\text { perawat. Hal ini pastinya akan } \\
\text { menimbulkan lamanya masa perawatan dan } \\
\text { penyembuhan pasien. }\end{array}$ \\
\hline 6. & $\begin{array}{l}\text { Benar } \\
\text { dokumentasi }\end{array}$ & $\begin{array}{l}\text { Perawat mencatat tindakan } \\
\text { pemberian obat kepada } \\
\text { pasien di status dan buku } \\
\text { obat pasien }\end{array}$ & $\begin{array}{l}\text { Kesalahan dalam hal dokumentasi paling } \\
\text { banyak ditemui dilakukan oleh sekitar } \\
60,0 \% \text { perawat. Didalam teori } \\
\text { pendokumentasian yang baik dan benar } \\
\text { (Indracahyani, 2010) bahwa dokumentasi }\end{array}$ \\
\hline
\end{tabular}




\begin{tabular}{|l|l|l|}
\hline & yang baik dan benar harus menyertakan \\
& nama dan tandatangan yang jelas si \\
pemberi obat ke pasien tersebut, didalam \\
rekam medic petunjuk pemberian obat \\
didokumentasikan dengan cara hanya \\
mencentang saja buku pemberian obat, hal \\
ini kurang tepat.
\end{tabular}

Hasil Uji Regresi Logistik Ganda Pengaruh Gaya Kepemimpinan, Budaya Organisasi, dan Role stress Terhadap Ketepatan Pemberian Obat oleh Perawat di di RSUD Kanujoso Djatiwibowo Balikpapan Tahun 2018

menyebabkan ketidaktepatan pemberian obat oleh perawat 4,332 kali lebih tinggi daripada budaya organisasi tinggi.

\section{Pembahasan}

Berdasarkan jenis kelamin, didominasi oleh perawat perempuan, 95\% C berdasarkan umur didominasi oleh

\begin{tabular}{|c|c|c|c|c|}
\hline Variabel & B & Sig. & $\operatorname{Exp}(B)$ & $\begin{array}{r}\text { EXI } \\
\text { Lower }\end{array}$ \\
\hline Transformasional & 1,559 & 0,003 & 4,755 & 1,687 \\
\hline Transaksional & 1,044 & 0,037 & 2,841 & 1,063 \\
\hline $\begin{array}{l}\text { Budaya } \\
\text { organisasi }\end{array}$ & 1,466 & 0,007 & 4,332 & 1,500 \\
\hline
\end{tabular}

Berdasarkan Tabel diketahui bahwa semua variabel independen berpengaruh secara signifikan terhadap ketepatan pemberian obat, masingmasing ditunjukkan dengan perolehan nilai $\mathrm{p}<0,05$. Gaya kepemimpinan memiliki nilai OR terbesar yaitu 4,755 [IK95\% = 1,687-13,403], artinya gaya kepemimpinan transformasional yang rendah akan menyebabkan ketidaktepatan pemberian obat oleh perawat sebesar 4,755 kali lebih tinggi daripada gaya kepemimpinan transformasional tinggi.

Nilai OR gaya kepemimpinan transaksional sebesar 2,841 [IK95\% = 1,063-7,592], artinya gaya kepemimpinan transaksional yang rendah akan menyebabkan ketidaktepatan pemberian obat oleh perawat sebesar 2,841 kali lebih tinggi daripada gaya kepemimpinan transaksional tinggi. Nilai OR budaya organisasi sebesar 4,332 [IK95\%=1,500-12,516], artinya budaya organisasi yang rendah akan
EXPıperawat di tingkatan umur remaja akhir dan rata-rata memiliki pengalaman kurang dari 8 tahun.

Poin tertinggi yang kedua yang harus menjadi catatan adalah setiap 1perawat wajib dan harus mengecek gelang dan memanggil nama pasien pada saat akan dilakukan tindakan medis maupun keperawatan kepada pasien hal ini akan memberikan efek nyaman dan tenang baik dari segi perawat sendiri maupun dari segi pasien.

Apalagi pada saat dilakukan penelitian ini ada kegiatan perbaikan sarana dan prasarana yang menyebabkan pasien berpindah-pindah tempat, hal ini dirasa oleh peneliti menjadi hal yang sangat rawan terjadi kesalahan dalam pemberian obat dan tindakan medis apabila pengecekan gelang identitas pasien ini tidak dilakukan

Gaya kepemimpinan transformasional yang tinggi dalam penelitian ini ditunjukkan oleh cara atasan mengajukan tujuan yang ingin dicapai dan menyerahkan cara pencapaiannya kepada perawat, pemberian tantangan pekerjaan kepada perawat, atasan memberikan contoh bagaimana mencapai kesuksesan berkarir pada bawahan, atasan memotivasi bawahan untuk menjadi ahli di bidang masing-masing, dan atasan dapat 
meningkatkan rasa bangga, kekaguman, dan bisa menjadi panutan bagi bawahan.

Persepsi terhadap gaya kepemimpinan transformasional yang tinggi atau efektif tersebut diikuti dengan kinerja perawat yang baik dalam hal ketepatan pemberian obat Alloubani, Almatar, dan Almukhtar (2014)

Budaya organisasi di rumah sakit sudah menunjukkan kebebasan dalam pemberian maupun penyampaian informasi, namun hal ini hanya dirasakan pada wilayah top manajer dan pada lini perawat pelaksana atau dibawah masih cenderung apabila ada masalah ditutuptutupi bahkan apabila bisa hanya akan diselesaikan secara intern saja (Agustina 2015). Hal ini tampak dari $29,6 \%$ perawat yang mengatakan bahwa budaya organisasi rumah sakit termasuk rendah.

Pada penelitian ini ketidakjelasan peran perawat tersebut terutama ditunjukkan oleh rencana dan tujuan pekerjaan yang tidak jelas, tidak dapat membagi waktu dengan baik karena harus menyelesaikan pekerjaan di berbagai tempat, tidak tahu dengan jelas harapan rumah sakit sakit terhadapnya, tidak jelas tentang pekerjaan yang seharusnya dilakukan dan tidak memahami wewenang yang saat ini dimiliki. Ketidakjelasan peran tersebut pada akhirnya menyebabkan ketidaktepatan pemberian obat.

Kelebihan peran yang dialami oleh perawat di RSUD Kanujoso Djatiwibowo Balikpapan berdasarkan tingkatan frekuensinya antara lain perawat memiliki terlalu banyak pekerjaan untuk dilaksanakan pada suatu waktu tertentu, standar pekerjaan yang dibebankan terlalu tinggi, dibebani pekerjaan yang bukan tanggung jawabnya, dibebani pekerjaan dengan kapasitas berlebih yang seharusnya dilakukan lebih dari satu orang, dan harus menyelesaikan pekerjaan pada waktu yang sama saat periode peak season.

\section{Kesimpulan dan Saran}

Gaya kepemimpinan yang paling berhubungan dengan ketepatan pemberian obat adalah gaya kepeminpinan transformasional, hal ini sesuai dengan data demografi pendidikan perawat yang mayoritas adalah diploma, mereka lebih menyukai pekerjaan yang telah ditetapkan dan diatur oleh kepala ruangan.

Budaya organisasi di rumah sakit sudah menunjukkan kebebasan dalam pemberian maupun penyampaian informasi, namun hal ini hanya dirasakan pada wilayah top manajer dan pada lini perawat pelaksana atau dibawah masih cenderung apabila ada masalah ditutuptutupi bahkan apabila bisa hanya akan diselesaikan secara intern saja. Sehingga budaya pelaporan apabila terjadi insiden pelanggaran juga minimal dilakukan oleh ruangan.

Penelitian lebih lanjut pada tingkat konflik yang lebih kompleks terkait konflik antar profesi, antar bagian dan antar institusi akan bermanfaat untuk meningkatkan kinerja antar profesi guna menuju kepemimpinan klinik yang baik dan dalam pengelolaan rumah sakit yang lebih berkualitas.

\section{Daftar Pustaka}

Agustina, L., 2015, Pengaruh Konflik Peran, Ketidakjelasan Peran Dan Kelebihan Peran Terhadap Kepuasan Kerja Dan Kinerja Auditor (Penelitian Pada KAP Yang Bermitra Dengan KAP Big Four Di Wilayah DKI Jakarta), Jurnal Akuntansi, 1(1):40-69.

Alloubani AM., Almatari M., Almukhtar MM., 2014, "Review: Effects of Leadership Styles on Quality of Services In Healthcare", European Scientific Journal June 2014 edition vol.10, No.18 ISSN: 1857 - 7881 (Print) e - ISSN 1857- 7431.

Fanani, dkk., 2018, Pengaruh Struktur Audit, Konflik Peran dan 
Ketidakjelasan Peran Terhadap Kinerja Auditor, Jurnal Akuntansi dan Keuangan Indonesia, 5(2): 139-155.

Hidayat, A. A. A., dan M. Uliyah, 2014, Kebutuhan Dasar Manusia. Jakarta: EGC.

Indracahyani A, 2010, Keselamatan Pemberian Medikasi, Jurnal Keperawatan Indonesia, Volume 13, No. 2, Juli 2010, 105-111.

Indriantoro, N. dan B. Supomo, 1999, Metode Penelitian Bisnis untuk Akuntansi dan Manajemen, Yogyakarta: BPFE.

Iroegbu M.N. 2014."Impact of Role Overload on Job Performance among Construction Workers". Asian Journal of Social Sciences and Management Studies Vol. 1, No. 3, 83-86.

Janovich, Jay. Joeana, Young. Daniel, R. Denison and Hee Jee. 2006. Diagnosing Organizational Culture: Validating a Model and Method for Support that they have provided for this research. The international Institute for Management Development and the University of Michigan Business School.

Jogiyanto, 2012, Metodologi Penelitian Bisnis: Salah Kaprah Dan Pengalaman-Pengalaman, Yogyakarta: BPFE.
Lawalata, dkk., 2016. Pengaruh Independensi Auditor, Komitmen Organisasi, Gaya Kepemimpinan Dan Budaya Organisasi Terhadap Kinerja Auditor.

Luthans, Fred. 2016, Organizational Behaviour. New york, McGrawHill

Maulana, I., 2012, Pengaruh Struktur Audit, Konflik Peran, Ketidakjelasan Peran Dan Locus Of Control Terhadap Kinerja Auditor (Studi Empiris Pada KAP Di Pekanbaru Dan Batam), Universitas Riau.

Robbins, S. P., 2013, Perilaku Organisasi, Jakarta: Salemba Empat.

Sabri L. dan Sutanto PH. 2010.Statistik Kesehatan. Cetakan Keempat. Jakarta: PT Raja Grafindo Persada

Swanburg, R. C., 2010, Kepemimpinan dan Manajemen untuk Perawat Klinis. Jakarta: EGC.

Trisnaningsih, S., 2017, Independensi Auditor Dan Komitmen Organisasi Sebagai Mediasi Pengaruh Pemahaman Good Governance, Gaya Kepemimpinan Dan Budaya Organisasi Terhadap Kinerja Auditor, Simposium Akuntansi Nasional X Makasar. 